\title{
Mission of Social Entrepreneurship in Modern Russia
}

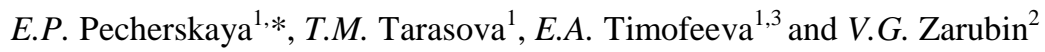 \\ *Corresponding author: pecherskaya@sseu.ru \\ ${ }^{1}$ Samara State University of Economics, Samara, Russia \\ ${ }^{2}$ Herzen State Pedagogical University of Russia, St.Petersburg, Russia \\ ${ }^{3}$ Research Institute of the Federal penitentiary service of Russia, Moscow, Russia
}

\begin{abstract}
The article discusses the essential characteristics of social entrepreneurship. The authors emphasize that the origins of social entrepreneurship in entrepreneurship is a special kind of market behavior. Creating and establishing intersectoral cooperation that will meet economic and social needs will enable success in this area. Our country still lacks a legislative initiative and a clear policy aimed at the development of this phenomenon. Society needs to be prepared for the fact that many social problems can be solved not only by the state, but also by private individuals seeking to make the world at least a little bit better. It's necessary to form among young people the correct idea of social entrepreneurship and how with their own resources and with the support of specialized organizations one can achieve the solution of many pressing problems of our time. From the standpoint of the formation and development of entrepreneurial qualities, the education system should contribute to a change in value orientations, equip the population with sustainable knowledge, skills and abilities in the field of entrepreneurship, motivate the individual to this activity, which requires finding and implementing new approaches to the content and organization of the educational process for all levels of education. The article shows the results of a study on the problems of the process of formation of entrepreneurial competence among students. The research showed the presence of entrepreneurial skills and a desire to implement it at the end of the learning process. A good step towards the development of this type of business would be the emergence in universities of a developed entrepreneurial infrastructure, moreover, aimed at solving social problems in society.
\end{abstract}

Keywords: social entrepreneurship, interaction efficiency, society, social problems, profit.

\section{Introduction}

To understand the meaning of the term "social innovation", the definitions given by individual theorists were analyzed by Battilana \& Lee [1], Bornstein [2], Dacin et al. [3], Dey \& Steyaert [4], Harding [5], Hossain et al. [6], Kraus et al. [7], Mair \& Marti [8], Somerville [9], Starik et al. [10], Starnawska [11], reputable international organizations that promote social entrepreneurship in general and support social projects: Schwab Foundation, Skoll Foundation, Social Enterprise London, The Social Enterprise Coalition, Ashoka Foundation, as well as discussion opinions presented on the New Business: Social Entrepreneurship Portal.

Anyway, the majority of citizens are included in various aspects of entrepreneurship. At the same time, the population is not ready to respond to modern challenges. This is due to the fact that the majority of citizens lack not only the necessary but also minimal knowledge in the field of entrepreneurial activity. The latter circumstance leads to the reluctance of the individual to become subjects of entrepreneurship, and in this case, it inevitably turns into an object of entrepreneurship, an object of manipulation.

In connection with the foregoing, the formation of entrepreneurial skills becomes the most important task of the successful socialization of citizens, the development of the country. Unfortunately, the Russian education system does not fully meet the new challenge of the time. In terms of the preparation of business entities, education focuses on the development of foreign researchers, which are based on a clear understanding of the individual that they must necessarily enter into entrepreneurial relationships throughout their lives, if not necessarily, then at will. For decades in our country, the opinion was formed that entrepreneurship is a criminal path of development (shadow economy) and therefore participation in it`s not only immoral, but also criminalized. Therefore, neither the population nor the education system turned out to be ready to restructure in a short time. Unfortunately, the research of Russian scientists in this field is contradictory and, as a result, ineffective.

\section{Problem Statement}

From the standpoint of the formation and development of entrepreneurial qualities, the education system should contribute to a change in value orientations, equip the population with sustainable knowledge, skills and abilities in the field of entrepreneurship, and motivate the individual to this activity. What requires the search and implementation of new approaches in the content and organization of the educational process at all levels of education.

Entrepreneurial readiness is not an end in itself to prepare all students. Moreover, a significant part of them does not connect their future with entrepreneurship. However, in a market economy, in our opinion, every citizen and, especially, 
a specialist with a higher education should have strong competences in the field of entrepreneurship. After all, even without being specifically engaged in entrepreneurship, a person constantly enters into an entrepreneurial relationship: choosing goods and services from diverse proposals. The lack of entrepreneurial competencies has already led a huge number of Russians to the loss of material resources and even housing, and other negative consequences. However, there are serious contradictions that hinder the effectiveness of the socialization of students. This is a contradiction between the need to prepare a specialist for inclusion in entrepreneurial activity through the formation of his competence in the field of entrepreneurship and the mismatch of goals in solving this problem. Currently, the main goal of entrepreneurial training is to form students' readiness for entrepreneurial activity as the main labor activity, while it's necessary to build competence in the sphere of entrepreneurial relations for successful socialization in the condition of market relations. This contradiction necessitates the solution of an important socio-pedagogical problem: on the basis of understanding the experience of forming the competence of an individual in the field of entrepreneurship, identify principles, mechanisms, methods, and organizational and pedagogical conditions from the standpoint of modern requirements and for the future.

\section{Research Questions}

Given the need for further scientific and practical development of issues on the identified issues, the main areas of research in this article are the following:

- a research of the formation of entrepreneurial competence among students;

- research of the essence of social entrepreneurship, its features and identification of ways to improve the process of formation of entrepreneurial competence.

\section{Purpose of the Study}

In accordance with the designated problem area defined research objectives: Identification of students' intentions to organize a new enterprise. Analysis of the individual characteristics of students and their impact on the entrepreneurial activity of students. Studying the process of formation of entrepreneurial competence among students of the SSUE.

\section{Research Methods}

In order to study the process of formation of entrepreneurial competence among students, a sociological study was conducted. The study surveyed 100 students studying at the Samara State University of Economics on the bachelor's program and specialty. The average age of respondents is 21 years. Most of the students surveyed study in the third or fourth year. Respondents were asked to complete an online questionnaire survey on the topic "The problem of the process of formation of entrepreneurial competence among students". The results of the survey will be presented in summarized form in the conclusions section.

\section{Findings}

First of all, we found out the attitude of students towards entrepreneurs and the overwhelming majority of respondents $(71 \%)$ have a positive attitude towards people engaged in entrepreneurial activities. However, among the respondents there were not those who would have a negative attitude towards people who are engaged in entrepreneurship. Slightly more than a quarter (29\%) of the respondents are neutral towards entrepreneurs, which is clearly shown in Figure 1. Entrepreneurship in the ideas of young people is an attractive activity, and the majority of respondents $(67 \%)$ declare their desire to start their own business.

a)

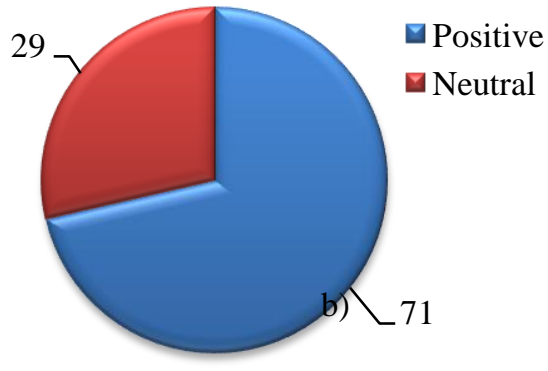

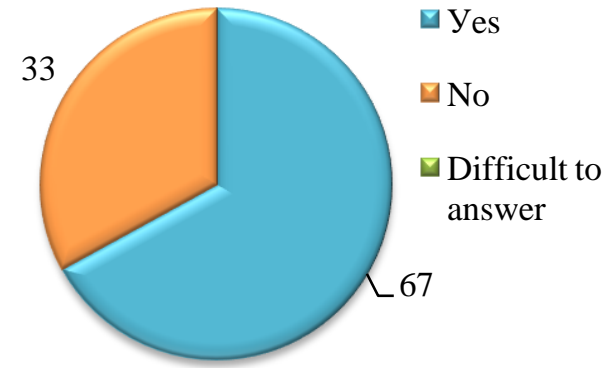

Figure 1. Answers of respondents to the question, \%

a) "How do you generally treat people who are engaged in entrepreneurial activities?",

b) "Do you plan to organize (continue) your business in the future?" 
Source: compiled by the authors.

Apparently, students expect that they can engage in small business after graduating. At the same time, among the students surveyed, no one conducts their own entrepreneurial activity at the present time. Thus, there is a significant gap between the current state of affairs and the respondents' expectations: young people, on the one hand, recognize the attractiveness, including financial, of small business, but on the other hand, they are not in a hurry to take active steps to organize their business.

In accordance with traditional ideas prevalent in society, entrepreneurial activity is more characteristic of men. In our opinion, this may correspond to the real situation, since the gender roles accepted in society have a significant influence on people's behavior, and, despite the changes taking place today regarding gender stereotypes, they have some inertia and in Russia have not yet reached that scale when it would be possible to talk about equal participation of the sexes in business activities. We considered the hypothesis: "We assume that entrepreneurial activity is more peculiar to men" and use the question: "Do you plan to organize (continue) your business in the future?" Table 1 presents the results.

Table 1. Answers of respondents to the question

"Do you plan to organize (continue) your business in the future?", \%

\begin{tabular}{|c|c|c|c|c|}
\hline \multirow{2}{*}{ Gender } & \multicolumn{4}{|c|}{ Plans to start its own business } \\
\cline { 2 - 5 } & Yes & No & Difficult to answer & Total \\
\hline Female & 25 & 27 & 0 & 52 \\
\hline Male & 42 & 6 & 0 & 48 \\
\hline Total & 67 & 33 & 0 & 100 \\
\hline
\end{tabular}

Source: compiled by the authors.

Given the maximum sampling error of 5\%, we calculate the range of students planning to start their own business, among girls and boys: Among girls: $20 \%<25 \%<30 \%$. Among boys: $37 \%<42 \%<47 \%$. Since the difference is significant, it should be concluded that the hypothesis is true: "Entrepreneurial activity is more characteristic of men".

To analyze the family business and succession in the field of entrepreneurship among the students participating in the survey, it was necessary to find out if there were any relatives or acquaintances who are doing business. During the study, we found out that the overwhelming majority of the respondents among relatives and friends have people who conduct their business $43 \%$ and $57 \%$, respectively. Although among the respondents there are those who are not familiar with entrepreneurs personally (19\%). In addition, it should be noted that none of the respondents is an entrepreneur and does not have his own business.

During the research, we found out the intentions of students regarding career choices. The expectations and intentions of students regarding their future career can be quite different. It often happens that the work that students choose immediately after graduation from a university does not coincide with their preferences in choosing a job five years later. Students gain more experience, and their career and professional intentions change. The study took into account this fact, and respondents were asked to answer two questions regarding career preferences: immediately after graduation and five years later. The answers to the questions were conditionally divided into four career options: employee, founder, successor. An employee works for hire in an existing company, the founder is an entrepreneur and establishes a new business, the successor inherits and takes over the management of the family business, the "Etc" column indicates the absence of a professional career, and there was also the option "Difficult to answer".

Most of the students immediately after graduation seek to get a job (66.6\%). Most of them want to work in a medium or large company (27.9 and $28.7 \%$ of the respondents). Only $15.6 \%$ of the sample strive to become founders immediately after graduation. Undecided career choices $-12.1 \%$ of respondents. The smallest part of the sample wants to inherit the family business $-5.7 \%$ of respondents.

The situation changes when it comes to career expectations five years after graduation. $60.1 \%$ of the students, which is more than half of the respondents, want to open their own company, i.e. become founders. The number of people willing to remain hired workers has decreased by almost $38 \%$ to $27.9 \%$. A greater number of respondents strive to become successors $-8.5 \%$. The undecided career choices dropped by almost $9 \%$, and is $3.5 \%$. In Russia, a large number of respondents think about opening their own business five years after graduation.

After analyzing the career preferences of students, it's not strange that within five years after graduation, young professionals mostly want to be employees. Having obtained the necessary theoretical knowledge, the students intend to test them in practice, to gain practical experience. Five years after graduation, many change their preferences in the direction of starting their own business. This can be explained by several reasons. First, having acquired the necessary experience, many young people dream of independence in choosing their place of work, and the best way to become independent is to create your own business. Secondly, entrepreneurship is becoming more and more prestigious, respected, socially-approved occupation, which gives, in addition to social security, also a material benefit. Thirdly, the material benefit is more distinct if you run your own business, and you are not an employee. It should also be noted a high percentage of respondents who have not decided on the choice of a career path, five years after graduation. Apparently, these students take into account the high level of uncertainty in the modern world and cannot yet tell how their career path will be formed five years after graduation. 
One of the most important analytical aspects of this report is the question of the barriers that prevent students from becoming entrepreneurs - to set up their business or take over the management of the family business from their relatives. These barriers should be studied and, if possible, removed to promote the development of entrepreneurship and infrastructure support for small and medium-sized businesses in the country.

The significance of the barriers to young entrepreneurs in the process of starting their own business are presented in Table 2. As can be seen, the most significant barrier is "access (its absence) to financial capital": $76.2 \%$. The second most important barrier is "bureaucracy, corruption, arbitrariness of officials" $52.4 \%$. Respondents considered the most insignificant barrier to be "insufficient support from the authorities and organizations promoting business development".

Table 2. Barriers to business

\begin{tabular}{|l|c|}
\hline \multicolumn{1}{|c|}{ Barriers to own business } & $\begin{array}{c}\text { Respondents' } \\
\text { Bnswers to the } \\
\text { question, \% }\end{array}$ \\
\hline \multicolumn{2}{|c|}{} \\
\hline There is no start-up capital, limited opportunities for obtaining a loan \\
\hline $\begin{array}{l}\text { Insufficient support from the authorities and organizations promoting business } \\
\text { development }\end{array}$ & 76.2 \\
\hline High tax burden & 14 \\
\hline Bureaucracy, corruption, arbitrariness of officials & 33.4 \\
\hline $\begin{array}{l}\text { Lack of knowledge and experience among people who want to start their own } \\
\text { business. }\end{array}$ & 52 \\
\hline \multicolumn{2}{|c|}{33} \\
\hline I could work for the company if I wanted to & 43.5 \\
\hline Limitation in long-term career & 10.2 \\
\hline Daily work in a team with parents / family members & 5.1 \\
\hline Responsibility for the successful continuation of the family tradition & 13.7 \\
\hline Disinterest in the offered goods or services & 27.5 \\
\hline
\end{tabular}

Source: compiled by the authors.

Another aspect of student entrepreneurial activity is the inheritance of the family business. It s important that there are also factors interfering with the normal course of this process. The results are presented in Table 2. Interestingly, the most significant barrier for the majority of respondents is "unwillingness to work in this company regardless of other barriers", which is $43.5 \%$. The most insignificant were "limitations in the long-term career" $(10.2 \%)$ and "daily work in a team with parents / family members" $(5.1 \%)$.

From the point of view of family business, the most pressing problem of succession is the unwillingness of children to inherit and manage their parents' business. Perhaps this is due to the desire to create something of their own, i.e. selfactualization (it's worth noting the high significance of the barrier "lack of interest in the products and services offered"), or with the unwillingness to do business at all, living happily, getting a rent, which is also a significant barrier.

The majority of respondents do not mind working in a family company if it would be interesting for them (43.5\%), this is also confirmed by lack of interest in the intended goods and services (27.5\%). Based on this, we can conclude that the hypothesis is confirmed.

The development of entrepreneurship competence among students is promoted by the availability of infrastructure to support entrepreneurship at the university: courses, seminars, business incubators, master classes, financial support, etc. To study this problem, the questionnaire included the availability of proposals in high school, i.e. factors in the development of entrepreneurial competence among students.

It should be noted that the most represented types of infrastructure support are "technological and search resources (library, Internet resources)" - 75.4\% of the respondents. At the same time, what is interesting, a significant majority of respondents would like to see seminars held by entrepreneurs (72\%), courses on entrepreneurship (61.4\%), and a business incubator (58.3\%) at the university.

Regarding the availability of higher education, in order to become an entrepreneur, respondents expressed as follows: the overwhelming majority of respondents $(66.7 \%)$ believe that higher education is mandatory for becoming an entrepreneur, although a third of the respondents, namely $33 \%$ believe that higher education is not a prerequisite for becoming a successful entrepreneur.

As for the respondents' opinion about a successful entrepreneur, the overwhelming majority (81\%) noted that this is a person who is professional in their field, and $57.1 \%$ of the respondents believe that if a person has been running a profitable business for many years, then he is successful entrepreneur. Speaking about the level of income, the majority of respondents, namely, $76.3 \%$ believe that entrepreneurial activity provides a higher level compared to employment, and $1 / 5$ of the respondents consider it exactly the opposite (Figure 2a). 
a)

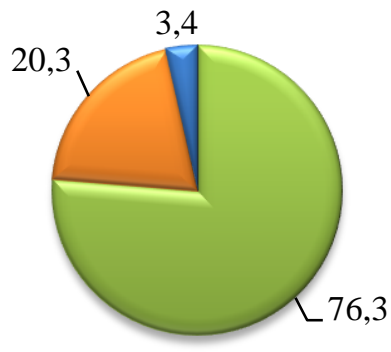

$\square$ Yes

$\square$ No

$\square$ Difficult to answer

b)

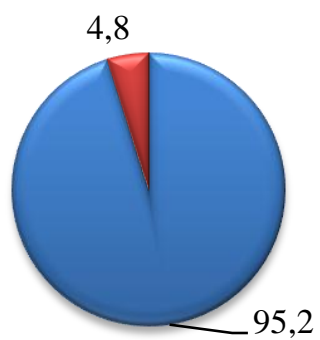

$\square$ Yes $\boldsymbol{\nabla}$ No

Figure 2. Answers of respondents to the question, \%

a) "Do business provide a higher level of income than employment?"

b) "Entrepreneurship gives more freedom and opportunities for self-realization than other work?"

Source: compiled by the authors.

Among the students surveyed, career as an entrepreneur is attractive because it can enhance the role of the individual in society, help to achieve recognition, independence and self-realization. According to the survey, $95.2 \%$ of respondents consider entrepreneurship to be an excellent way of self-realization (Figure $2 b$ ).

In accordance with this provision, entrepreneurship is an independent business activity of enterprising young people, not contradicting the law and based on certain resources, autonomous socio-economic initiative, innovation, personal qualities and responsibility, aimed at making profit and achieving material well-being, as well as free self-realization and self-assertion of a young man.

\section{Conclusion}

The mechanism for the development and support of social entrepreneurship is carried out without due attention of the state in Russia, the government does not think out enough mechanisms of assistance. Often, government agencies involved in supporting entrepreneurship reduce everything to the security itself, only fix problems and obstacles without giving proper assistance, and real support is of a single character.

In the course of the study, we identified problems in the formation of entrepreneurial competence of students of the SSUE. For the development of entrepreneurship there are many barriers, lack of capital, bureaucratic red tape and lack of knowledge. In addition, the lack of a well-developed infrastructure for training entrepreneurs at the university has an important impact.

\section{References}

1. J. Battilana, M. Lee, Advancing Research on Hybrid Organizing - Insights from the Study of Social Enterprises. Academy of Management Annals, 8(1), 397-441. DOI: 10.5465/19416520.2014.893615 (2014).

2. D. Bornstein, How to change the world: social entrepreneurs and the power of new ideas. Oxford: Oxford University Press (2004).

3. M. Dacin, P. Dacin, P. Tracey, Social entrepreneurship: A critique and future directions. Organization Science, 22(5), 1203-1213 (2011).

4. P. Dey, C. Steyaert, The politics of narrating social entrepreneurship. Journal of Enterprising Communities: People and Places in the Global Economy, 4(1), 85-108 (2010).

5. R. Harding, Understanding social entrepreneurship. Industry and Higher Education, 21(1), 73-84 (2007).

6. S. Hossain, M.A. Saleh, J. Drennan, A critical appraisal of the social entrepreneurship paradigm in an international setting: a proposed conceptual framework. International Entrepreneurship and Management Journal, 13(2), 347368. DOI: 10.1007/s11365-016-0400-0 (2016).

7. S. Kraus, M. Filser, M. O'dwyer, E. Shaw, Social Entrepreneurship: An Exploratory Citation Analysis. SSRN $\begin{array}{llll}\text { Electronic Journal, } & \mathbf{8}(2), & \text { 275-292.DOI: } & \text { 10.2139/ssrn.2601909. }\end{array}$ https://papers.ssrn.com/sol3/papers.cfm?abstract_id=2601909 (2014).

8. J. Mair, I. Marti, Social entrepreneurship research: A source of explanation, prediction and delight. Journal of World Business, 41(1), 36-44 (2006).

9. D. Somerville, Understanding social entrepreneurship: The relentless pursuit of mission in an ever changing world. Journal of Community Practice, 22, 491-493. DOI: 10.1080/10705422.2014.957567 (2014).

10. M. Starik, G. Rands, A. Marcus, T. Clark, From the guest editors: In search of sustainability in management education. Academy of Management Learning \& Education, 9(3), 377-383 (2010).

11. M. Starnawska, Social entrepreneurship research - challenges, explanations and suggestions for the field development. Problemy Zarzadzania, 14(3(61) t.1), 13-31. DOI: 10.7172/1644-9584.61.1 (2016). 